\title{
Cmambu
}

\section{КИНЕСТЕЗИЯ И ИСТОЧНИКИ ИНФОРМАЦИИ О ДВИЖЕНИИ, ПРЕДСТАВЛЕННОМ С РАКУРСА ОТ 1-ГО И ОТ 3-ГО ЛИЦА, У ЛЫЖНИКОВ-ГОНЩИКОВ РАЗЛИЧНОГО УРОВНЯ МАСТЕРСТВА}

\author{
И.В КАМИНСКИЙ ${ }^{a}$ О.В. АЛМАЗОВА ${ }^{\mathrm{a}}$, А.Н. ВЕРАКСА
}

`Московский государствениый университет имени М.В. Ломоносова, 119991, Россия, Москва, Ленинские горы, Ә. 1

\section{Резюме}

Настоящая статья посвящена изучению ракурса как формы существования мысленного образа, которая может быть охарактеризована различными свойствами с точки зрения возможности ее использования в спорте. В дополнение к кинестетической модальности, традиционно рассматриваемой спортивными психологами в качестве такого свойства, изучается использование различных способов оценки представленного движения на разных уровнях спортивного мастерства. Выборка состоит из 54 лыжников-гонщиков, квалификация которых охватила максимально возможный диапазон. Испытуемые представляли одновременный двухшажный коньковый ход в своем исполнении, последовательно концентрируясь на восьми его элементах, на основе которых было составлено 11 заданий. Каждое из них сопровождалось заполнением специально сконструированного опросного блока, обеспечивающего сбор данных о ракурсе и кинестетической модальности образа, а также способах контроля представленных движений, в основу выделения которых были положены признаки модальности (визуальная/невизуальная) и ориентира оценки их правильности (структура/результат движения). Мастерство спортсменов характеризовалось экспертными оценками техники исполнения семи задействованных при исследовании мысленного образа элементов одновременного двухшажного конькового хода и количеством циклов в двух лыжероллерных 100-метровых забегах, один из которых проводился в режиме совмещения двух задач. При помощи кластерного анализа были выделены группы, объединяющие спортсменов по преимущественно используемому ракурсу образов, а также по уровню мастерства. Распределения интенсивности кинестезии в зависимости от ракурса и способов контроля представленного движения внутри групп, выделенных по преимущественно

Работа выполнена в рамках проекта РГНФ, проект № 15-06-10294. 
используемому ракурсу, показали, что интенсивность кинестезии выше на фоне доминирующего ракурса, тогда как при ракурсе от 1-го лица возрастает частота использования невизуальных способов контроля, а при ракурсе от 3-го - визуального контроля внешней формы движения. Распределение способов контроля по мастерству соответствует уже известным аналогичным закономерностям для реальных движений, подтверждая эквивалентность лежащих в их основе процессов.

Ключевые слова: психология спорта, мысленный образ, мысленная тренировка, мысленная проработка, ракурс мысленного образа, перспектива образа, сенсорная модальность образа, кинестетическая модальность, кинестезия, контроль представленного движения, двигательные навыки, лыжные гонки.

В спортивной психологии уже давно закрепилось понимание мысленного образа как средства совершенствования двигательных навыков, подобного физическому выполнению соответствующих движений (Веракса, Горовая, 2011). Применение образа с этой целью известно как мысленная проработка двигательного навыка. Оптимизируя ее, как и другие методы спортивной подготовки, многие авторы (Каминский, 2015) допускали, что в зависимости от ракурса представления (т.е. представляет ли субъект свое движение визуально с собственной позиции от 1-го лица или со стороны, будто видит себя на экране телевизора, от 3-го лица) образ может в разной мере способствовать развитию прорабатываемых навыков.

В литературе (Hale, 1998; Jowdy et al., 1989) широко распространено мнение о том, что образы с ракурсом от 1-го лица лучше передают представляемое движение в кинестетической ${ }^{1}$ модальности, тогда как образы с ракурсом от 3-го лица менее тесно связаны с ней или вовсе ограничиваются лишь визуальным представлением. Из этого следует, что, представляя от 1-го лица, субъект задействует дополнительный (по отношению к представлениям от 3-го лица) и наиболее специфичный движению канал информации, в результате чего мысленная проработка от 1 -го лица должна давать более выраженный эффект.

Однако проведенный анализ работ по данной теме (Каминский, 2015) показал, что в настоящее время любые рекомендации, основанные на взаимосвязи ракурса и модальности мысленного образа, не имеют достаточного экспериментального подтверждения и, кроме того, существуют эмпирические данные, альтернативные вышеприведенной гипотезе (Callow, Hardy, 2004).

Многие авторы, по-видимому, интуитивно апеллируют к тому, что кинестезия является «телесным» чувством и испытать его возможно

${ }^{1}$ Кинестезия (от греч. kinetikos - «относящийся к движению» и aesthesis - «ощущение») содержание мысленного образа, соответствующее телесному ощущению определенной позы или движения. 
лишь изнутри - в образе от 1-го лица, а не отстраняясь от своего тела в образе от 3-го лица. С другой стороны, визуальные рамки образов от 1-го лица (в отличие от образов от 3-го) привязаны к естественному углу обзора субъекта, и поэтому действия, происходящие за пределами видимости, такие как движение рук за спиной, не могут быть полноценно переданы визуальной частью образа. Поскольку в этих условиях от потери информации о таком движении может предохранять только ее передача в кинестетической модальности, логично полагать, что в образе от 1-го лица кинестезия более развита, чем в образе от 3-го, ведь она является необходимым средством компенсации его визуальной ограниченности.

Но вне зависимости от истоков устоявшихся взглядов на взаимосвязь ракурса и модальности мысленного образа вопрос о ее истинной природе остается актуальным и определяет теоретическую значимость настоящей работы. Он подводит нас вплотную к дальнейшему решению прикладной проблемы, состоящей в обосновании или опровержении кинестезии как универсального аргумента для применения в спортивной подготовке мысленной проработки определенного ракурса.

Однако, чтобы полностью раскрыть намеченную тему, необходимо обратить внимание еще на одно потенциальное противоречие, разделяющее кинестетическое содержание образа по результатам непосредственной диагностики и его реальное использование в процессе мысленной проработки.

Исследуя кинестезию как таковую, мы можем спрашивать испытуе- мого, например, возникает ли у него в процессе того или иного представления мысленное чувство движения и/или мышечного усилия, а также можем просить его оценить интенсивность такого чувства. При этом у субъекта создается установка на поиск в образе кинестетического содержания, что смещает его внимание к отслеживанию мышечного чувства. Однако в остальное время представление субъекта может быть акцентировано, к примеру, на зрительном образе пространственной конфигурации движения как на индивидуально наиболее важном ориентире его правильности. Получив ответ на поставленный вопрос, мы констатируем для каждого случая отсутствие кинестезии или ее наличие с той или иной степенью выраженности.

Допустим, по итогам такого исследования было выявлено, что определенный тип мысленного образа превосходит другие по выраженности кинестезии. Но можем ли мы на таком основании рекомендовать использование образов именно этого типа с расчетом на то, что субъект в дальнейшем будет задействовать кинестезию в качестве одного из основных источников информации о представленном движении? Произойдет ли это в том случае, если привычная манера представления субьекта не имеет направленности на кинестетическое содержание? Если за счет акцента на кинестезии удастся получить повышение эффективности мысленной проработки, будет ли оно одинаковым у всех спортсменов или выделятся целевые группы, ограничивающие целесообразность такой рекомендации? 
Приведенное рассуждение и поставленные по его итогам вопросы уточняют предмет исследования не просто как кинестезию в образах того или иного ракурса, а как «полезную» кинестезию, служашую для субъекта источником информации о представленном движении. В результате появляются задачи сопоставления двух вышеназванных конструктов и изучения их взаимосвязей не только с другими особенностями мысленного образа (ракурс от 1-го или от 3-го лица), но и с потенциальными лимитирующими факторами. Поскольку в литературе известна смена основных источников информации о движении по мере освоения и совершенствования соответствующего моторного навыка (Бернштейн, 1990), уровень владения последним будет рассмотрен в качестве фактора, потенциально ограничивающего значимость кинестезии в двигательном образе ${ }^{2}$.

В результате для настоящей статьи может быть обозначен следующий круг задач:

1) выделить возможные типы источников информации о представленном движении, операционализировать и применить соответствующую систему конструктов;

2) изучить взаимосвязь между ракурсом мысленного образа и

a) его кинестетичеким содержанием по результатам непосредственной диагностики традиционным опросным методом;

б) основным источником информации о представленном движении;
3) соотнести показатели выявленной традиционным опросным методом кинестезии и «полезной» кинестезии, используемой в качестве источника информации о представленном движении;

4) описать динамику изменений используемых источников информации о представленном движении по мере роста уровня владения двигательным навыком.

\section{Методика}

В исследовании участвовали 54 лыжника-гоншика (14 девушек) в возрасте от 11 лет до 31 года $(\mathrm{SD}=5.26)$. Большой разброс возраста испытуемых объясняется необходимостью набрать спортсменов в максимально широком диапазоне мастерства, продиктованной задачами исследования. В числе респондентов 7 лыжников имели спортивный разряд от 3-го до 1-го юношеского, $24-3$-й или 2-й, 13 - 1-й или «кандидат в мастера спорта» (КМС), 10 - звание «мастер спорта» (МС), в числе которых 8 выступали в составе сборной команды России и имели звания МС международного класса и заслуженного МС.

\section{Исследование мысленного образа}

Исследование выполнено на основе специально сконструированного опросного блока, состоящего из 11 одинаковых частей (структура опросного блока на примере одной части представлена в приложении 1).

${ }^{2}$ С учетом теории об эквивалентности процессов, лежащих в основе мысленно представленного и реально вьполненного двигательного действия (Jeannerod, 1994). 
Каждая из них адресована диагностике особенностей мысленного образа одного из элементов равнинного варианта одновременного двухшажного конькового хода (ОДКХ). Перечень этих элементов был сформирован совместно со специально приглашенными экспертами ${ }^{3}$, в него вошли составляюшие хода, наиболее значимые для оценки чистоты технического исполнения последнего, а именно: вынос палок, постановка палок, подсед и толчок ногой, навал на палки, сохранение угла в локтевом суставе при навале на палки, выход на опорную ногу с сохранением равновесия, доталкивание, разгиб таза. При этом вынос палок был задан в двух вариантах, отличающихся ориентирами правильности исполнения: «не ниже уровня макушки» - в первом случае и «до уровня глаз» - во втором; доталкивание давалось в трех вариантах описания, из которых один был нейтрален по отношению к модальности («Полный разгиб рук в локтевом суставе при доталкивании»), а другие рассчитаны на акцентирование телесного ощущения («палка действует как продолжение руки») или визуальной картины («рука и палка образуют прямую линию») $)^{4}$. Таким образом, было получено 11 формулировок-описаний технических элементов, каждый из которых лыжники представляли в своем исполнении несколько раз, и в сопровождении экспериментатора они указывали в опросном блоке следующие особенности своего наиболее привычного представления.

1. Визуальная модальность: ракурс

Перед началом заполнения опросного блока респондентам подробно разъяснялся смысл, вложенный в понятия «ракурс от 1-го лица» и «ракурс от 3-го лица». На основе полученных знаний испытуемые относили свое представление к категориям: «с ракурсом от 1-го лица», «с ракурсом от 3-го лица» или «с ракурсом, меняющимся в процессе представления» - и наносили соответствующую отметку на специальную аналоговую шкалу (Spittle, 2001). В соответствии с последней ракурс от 3-го лица учитывался в процедурах дальнейшего анализа в виде числового эквивалента в 10 баллов, ракурс от 1-го лица - в виде эквивалента в 0 баллов, а каждый промежуточный балл рассматривался как эквивалентный временной пропорции представления от 3-го лица в случае смены ракурса (например, 3 балла - представление $30 \%$ по времени от 3-го и 70\% по времени от 1 -го лица).

2. Кинестетическая модальность

A. В номинальном выражении: испытуемые сравнивали представление одного и того же двигательного элемента с ракурса от 1-го и от 3-го лица по суб́ьективно ощущаемой в образе интенсивности кинестезии. Результат сравнения фиксировался в виде одного из следующих вариантов

${ }^{3}$ Для консультации по вопросам, связанным с анализом технической стороны деятельности лыжника, а также для оценки технического мастерства испытуемых были привлечены два эксперта из тренерского состава сборной России по лыжным гонкам.

${ }^{4} \mathrm{~B}$ скобках приводится точная формулировка использованного описания. 
ответов: движение и мышечное усилие ощущается при представлении «только от 1-го лица», «только от 3-го лица», «от 1-го лица более интенсивно», «от 3-го лица более интенсивно», «с одинаковой интенсивностью вне зависимости от ракурса» или ощущение «отсутствует вне зависимости от ракурса».

Б. В количественном выражении: субъективно ощущаемая в образе интенсивность кинестезии передавалась в виде баллов от 0 (представление исключительно в визуальной модальности с полным отсутствием кинестетического содержания) до 10 (ясность кинестезии приравнивалась к чувству реально выполняемого движения).

3. Источники информации о представленном движении

Признаком, традиционно принятым для описания особенностей мысленного образа и образной сферы, является модальность. Модальность определяется как качественная характеристика перцептивных элементов, отражающая их специфичность какому-либо органу чувств (Барабанщикова, 2005), что позволяет субъективно различать тот или иной образ восприятия как продукт активности определенной сенсорной системы. В соответствии с типом анализатора, опосредующего первичное восприятие, выделяют модальности: зрения, слуха, осязания, вкуса, обоняния (внешние), а также равновесия, движения, соматических ощущений боли, температуры, голода и жажды (внутренние) (Дубровский, 2007). Образ двигательного действия, как правило, полимодален, однако считается, что наиболее существенная его часть, несущая исчерпывающую информацию о движении, представлена визуальной и кинестетической (в том числе вестибулярной) модальностью (Барабаншикова, 2005; Бернштейн, 1990; Ives, 2013). Так, например, С.П. Елшанский (2014) отмечает, что при воспроизведении определенной позы руки испытуемые ориентируются именно на ее визуальный или кинестетический образ и, как правило, одна из этих модальностей значимо доминирует над другой (Барабанщикова, 2005; Елшанский, 2014).

Таким образом, спрашивая, оценивается ли правильность представленного движения по визуальным ориентирам или на уровне телесного ощущения, мы сможем охарактеризовать значимую для субъекта информацию о данном движении с позиции передаюшей ее сенсорной системы. Однако важно учесть возможные различия не только процессов восприятия, но и самого воспринимаемого содержания, определяемого особенностями ориентиров, по которым оценивается движение. Пример работы с такими особенностями в рамках исследования мысленного образа известен из статьи А. Гуиллота с соавт. (Guillot et al., 2013), которые предлагали теннисистам различного уровня мастерства в процессе мысленной проработки подачи концентрироваться либо на движении руки, выполняющей удар по мячу, либо на последующей траектории полета мяча и высоте его прохождения над сеткой. В итоге ключевым ориентиром при представлении может являться как структура самого движения, так и его необходимый результат. 
Таким образом, в рамках настоящего исследования предложено выявлять характер значимой для субъекта информации о представленном движении по двум признакам: модальности ее воспроизведения и содержанию (ориентиру правильности). В соответствии с вышеприведенным описанием для каждого из этих признаков допускается по два возможных проявления (см. таблицу 1), так что на их пересечении можно установить четыре вида информации о представленном движении и, соответственно, четыре вида его субъект ивного оценивания.

Представленные в таблице 1 виды субъективной оценки движения использовались в качестве вариантов ответа на вопрос, к которому давалось устное пояснение следующего содержания:

«У вас есть собственное субъективное представление об идеальном, с вашей точки зрения, исполнении рассматриваемого движения как о таком, к которому вы стремитесь, снова и снова предпринимая его. И, каждый раз повторяя данное движе- ние (физически или мысленно), вы способны определить, насколько текущее исполнение близко к идеальному в вашем понимании. А теперь постарайтесь ответить, на что же вы склонны опираться, выполняя такую оценку представленного мысленно конкретного движения?»

Хорошее понимание задания испытуемыми достигалось за счет простоты разделения понятий «действие»/《результат» и «я вижу»/《я ощущаю» на самом элементарном бытовом уровне. Отвечая на данный вопрос, испытуемые не были ограничены выбором какого-либо одного варианта, поскольку мы допускали, что различные способы контроля представленного движения могут взаимодополнять друг друга или использоваться в различных целях.

\section{Оценка спортивного мастерства}

Поскольку такие показатели, как спортивный разряд, зачастую неточно отражают действительный уровень владения спортсменами соответствующим двигательным навыком

Таблица 1

Предложенные виды субъективной оценки представленного движения

\begin{tabular}{|l|l|l|}
\hline \multirow{2}{*}{$\begin{array}{c}\text { Модальность } \\
\text { восприятия }\end{array}$} & \multicolumn{1}{|c|}{ Ориентир правильности } \\
\cline { 2 - 3 } Втруктура движения & \multicolumn{1}{|c|}{ Результат движения } \\
\hline Визуальная & $\begin{array}{l}\text { (1) Оценка движения «по внешней } \\
\text { форме» }\end{array}$ & $\begin{array}{l}\text { (2) Оценка движения «по } \\
\text { результату» }\end{array}$ \\
\hline Невизуальная 5 & $\begin{array}{l}\text { (3) Оценка движения «по } \\
\text { мышечной памяти» }\end{array}$ & $\begin{array}{l}\text { (4) Оценка движения «по } \\
\text { ощущению результата» }\end{array}$ \\
\hline
\end{tabular}

${ }^{5}$ Учитывая, что результат действий лыжника выражается в дальности проката и ускорении (передвижение тела в пространстве), его ощущение будет формироваться из вестибулярных рецепций в отличие от ощущения самого движения, в основе которого лежат мышечно-суставные рецепции (передвижение частей тела относительно друг друга). 
(Веракса и др., 2011), техническое мастерство оценивалось в двух лыжероллерных забегах, один из которых проводился в режиме совмещения двух задач (англ. dual-task method). По утверждению Б. Абернети и др., данная методика позволяет проранжировать спортсменов в соответствии с их мастерством более точно, чем это удается сделать, оценивая их координацию путем проведения двигательных тестов в обычных условиях (Abernethy et al., 1998)

Для этого был выбран прямой равнинный участок (длина - 100 м) лыжероллерной трассы, расположенный на выходе из поворота (рисунок 1). От его середины в перпендикулярном направлении отсчитывалось 50 м, где на штативе устанавливалась видеокамера Sony HDR-SR12E. B обоих забегах лыжники должны были пройти тестовый участок трассы, используя ОДКХ и самостоятельно контролируя быстроту передвижения, ориентиром для которой служила их среднесоревновательная скорость на дистанции 5 км.
Второй забег отличался необходимостью выполнения дополнительного задания, которое наделялось приоритетным статусом по отношению к основной задаче. Задание в зрительной модальности было выбрано как более специфичное деятельности лыжника и снижающее визуальный контроль за выполняемыми движениями. Также задание подбиралось с учетом того, чтобы предъявление стимулов и регистрация ответной реакции не создавали непосредственных препятствий основной деятельности (Ibid.).

Стимульный материал был нанесен на листы формата A0 и размещался на 5 флипчартах, которые выставлялись через каждые 20 м от начала тестового участка вдоль дальней от камеры кромки трассы (рисунок 1). Каждый из них демонстрировал сетку $3 \times 3$ квадрата, один из которых имел в центре черную точку диаметром $1.5 \mathrm{~cm}$ (все участники подтвердили, что хорошо видят ее с расстояния $20 \mathrm{~m}$ ). От испытуемых требовалось зафиксировать в уме

Рисунок 1

Схема подготовленного к проведению забегов участка трассы

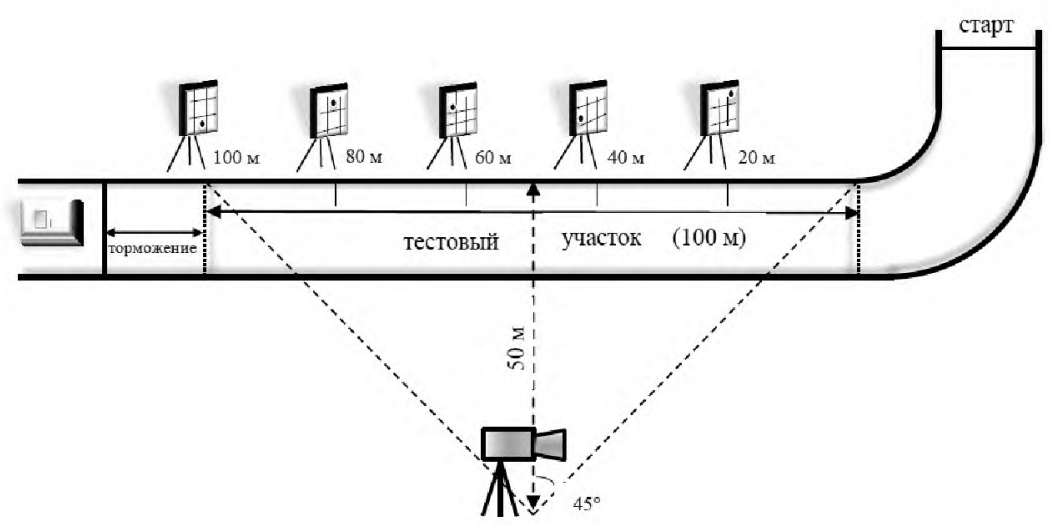


последовательное расположение пяти точек, мысленно построив кривую, соединяющую их (см. приложение 2). Затем полученная кривая воспроизводилась на специальном бланке, выложенном на столе, который был установлен на расстоянии 15-20 м от конца тестового участка.

На базе полученных видеоматериалов:

1) выносились әкспертные оченки за чистоту исполнения каждого из базовых 8 технических элементов вышеприведенного перечня (см. пункт «Исследование мысленного образа»), кроме элемента «сохранение угла в локтевом суставе», который, по мнению экспертов, не мог быть оценен на основе представленных видеоматериалов. Поскольку во втором забеге создавались условия, задействующие те когнитивные ресурсы лыжников, которые могли быть использованы для контроля за движением, сумму разностей соответствующих друг другу экспертных оценок первого и второго забегов мы условно обозначили как показатель деавтоматизации движения на фоне сбивающего воздействия;

2) подсчитывалось иисло ииклов на срединных 60 м тестового участка. Как известно, количество двигательных циклов, затрачиваемых на преодоление одной и той же дистанции, уменьшается по мере роста мастерства в связи с возрастающей эффективностью отталкивания (Раменская, 1999) и способностью удерживать равновесие при одноопорном скольжении (Новикова, 2014). По аналогии с экспертными оценками предполагается, что прирост числа циклов во втором забеге также будет характеризовать уровень владения двигательным навыком, отражая его устойчивость к сбивающему воздействию.

\section{Статистическая обработка данных}

Для группирования спортсменов по преимущественно используемому ракурсу мысленных образов, а также по уровню технического мастерства применен кластерный анализ методом k-средних с возможностью произвольного выбора количества кластеров. Связи между ракурсом мысленного образа, интенсивностью кинестезии, частотой использования различных видов оценки представленного движения и уровнем технического мастерства анализировались c расчетом критерия Хи-квадрат Пирсона (для номинальных переменных) и коэффициента ранговой корреляции Спирмена (для количественных переменных). Сравнение различных групп спортсменов по интенсивности кинестезии в количественном выражении выполнялось с помощью критерия Манна-Уитни для независимых выборок. Аппроксимация динамики изменения оценки кинестезии (в номинальном выражении) с возрастом испытуемых к линейной модели выполнена методом регрессионного анализа. Статистическая обработка проведена на базе пакета SPSS 17.0 для Windows.

\section{Результаты}

Группировка спортсменов по преимущественно используемому ракурсу мьсленньх образов

Получено три группы, составляющие 33, 40 и 27\% выборки, соответ- 
ственно: испытуемые, склонные представлять движения от 1-го лица; предрасположенные к смене ракурса в процессе представления; склонные представлять движения от 3-го лица.

\section{Группировка спортсменов по уровню мастерства}

Проведен кластерный анализ с учетом средней оценки за технику в первом забеге (коэффициент корреляции Спирмена между оценками двух экспертов $r=0.930, p<0.001$ ), показателя деавтоматизации движения, а также количества циклов в первом и во втором забеге. Основная масса испытуемых $\left(n_{1}=46\right)$ была разделена на четыре группы: от низкого до очень высокого уровня мастерства; в отдельную группу как лыжники экстра-класса были выделены члены сборной $\left(\mathrm{n}_{2}=8\right)$. Процентное распределение испытуемых по полученным группам можно видеть на рисунке 2.

Рисунок 3 иллюстрирует отношения между выделенными уровнями мастерства и имеющейся у спортсменов квалификацией. На основании данных диаграммы можно заключить, что усматривается логическая согласованность между предложенным делением спортсменов по уровню мастерства и их фактической квалификацией, что оправдывает использование выделенных групи при проведении дальнейших расчетов. Кроме того, интересен тот факт, что самый большой размах по полученным уровням мастерства наблюдает ся исключительно среди лыжников 2-3-го разряда. Это может свидетельствовать о том, что на данном этапе уже находят свою реализацию заложенные в юных спортсменах способности, за счет чего ярко проявляются различия в темпах формирования двигательного навыка. В такой ситуации отстающие спортсмены могут терять мотивацию к спорту и прекращать занятия.

Кинестетическая модальность мысленного образа по отношению к его ракурсу проявила себя в исследуемой

Процентное распределение выборки по группам, выделенным на основе уровня спортивного мастерства

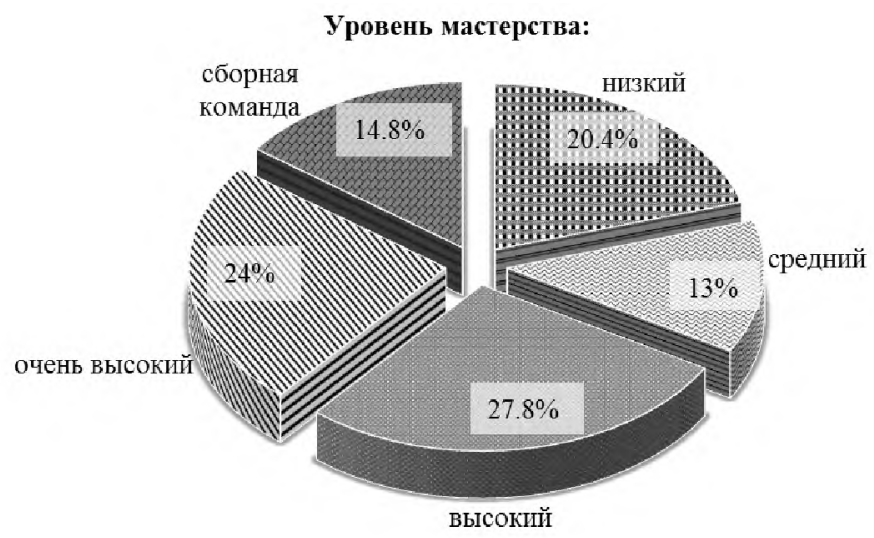


выборке во всех возможных номинальных выражениях, причем все они являются сопоставимыми по частоте (рисунок 4). Все же в общей массе испытуемых можно отметить несколько бо́льшую склонность мыс- ленно воспринимать движение в кинестетической модальности $\mathrm{c}$ ракурса от 1-го лица.

Распределение номинально выраженных (см. раздел «Методика») показателей кинестезии в группах

Рисунок 3

Процентное распределение спортсменов по полученным уровням мастерства внутри групा, выделенных на основе квалификации

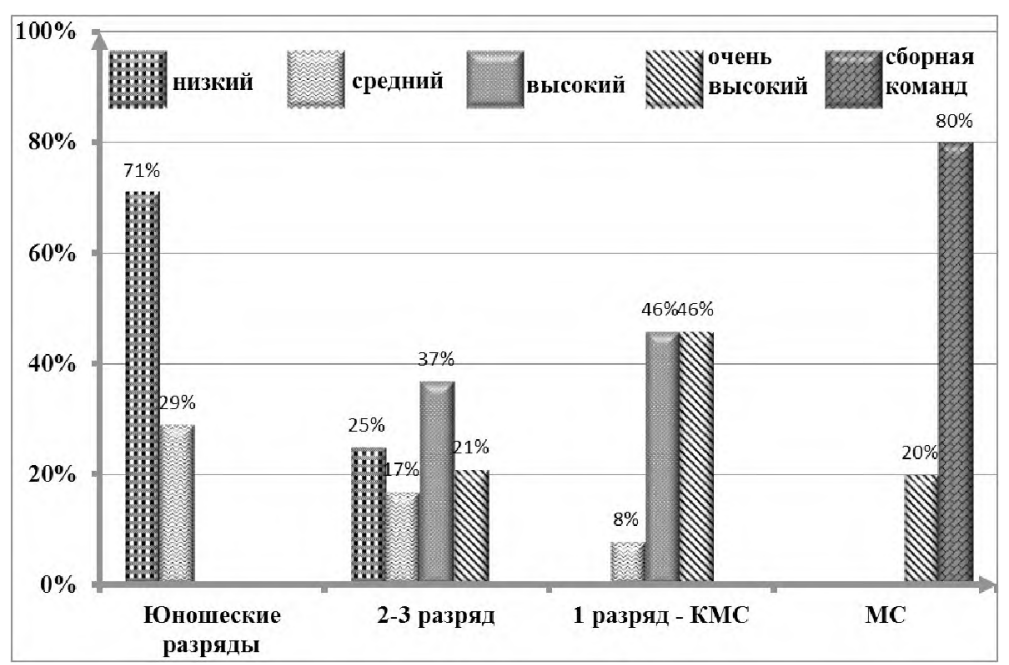

Рисунок 4

Частота встречаемости различных вариантов выраженности кинестезии в зависимости от ракурса мысленного образа в исследуемой выборке

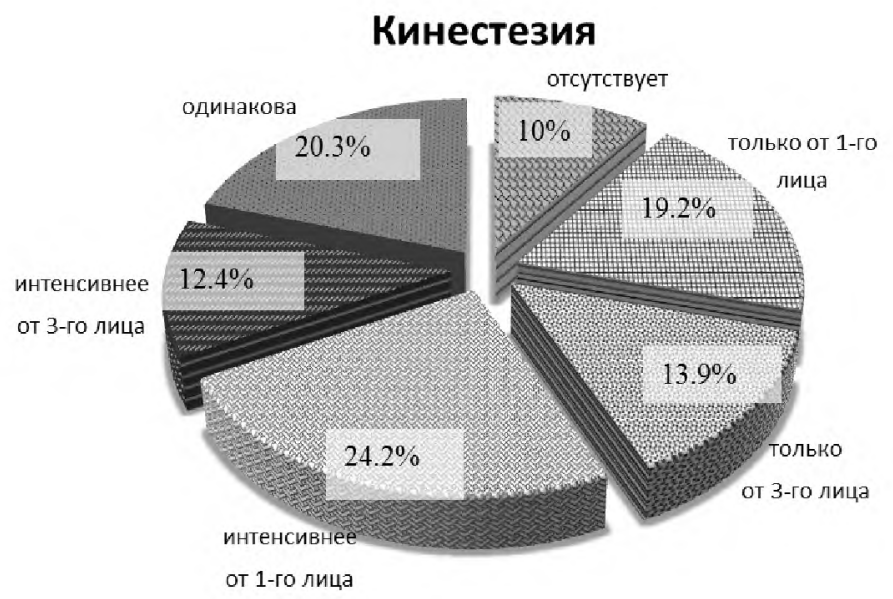


респондентов, выделенных на основе преимущественно используемого ракурса, значимо отличается от равномерного (таблица $2 ; \chi^{2}=95.783 ; p<0.001$ ). При этом представленное распределение позволяет увидеть сразу две закономерности.

Во-первых, ракурс от 1-го лица все же в большей мере предрасполагает к восприятию кинестетических ощущений по сравнению с ракурсом от 3-го лица. Об этом говорит совокупность следующих особенностей распределения:

1) более ясное восприятие кинестезии на фоне доминирующего ракурса чаще встречается в группе с преобладанием образов от 1-го лица, чем в группе с преобладанием образов от 3-го лица (60.4\% случаев против $48.7 \%$ );
2) недоминирующий ракурс чаще идентифицируется как более насыщенный кинестетически в группе с преобладанием образов от 3-го лица, чем в группе с преобладанием образов от 1-го лица (20.1\% случаев против $8.0 \%$ );

3) в группе с доминированием смены ракурса образы от 1-го лица чаще считаются связанными с более выраженным «чувством движения», чем образы от 3-го лица (45.2\% случаев против $26.3 \%$ ).

Во-вторых, испытуемые склонны лучше воспринимать кинестезию в образах доминирующего ракурса. Об этом свидетельствуют последовательное снижение частоты указания образов от 1-го лица и пропорциональное увеличение частоты указания образов от 3-го лица как более

Таблица 2

Распределение выраженности кинестезии в зависимости от ракурса мысленного образа в группах испытуемых, выделенных на основе преимущественно используемого ракурса

\begin{tabular}{|l|c|c|c|c|}
\hline \multirow{2}{*}{ Кинестезия } & \multicolumn{2}{|c|}{ Преимущестенно используемый ракурс } & \multirow{2}{*}{ Итого } \\
\cline { 2 - 4 } & От 1-го лица & Смена & От 3-го лица & \\
\hline \multirow{2}{*}{ Отсутствует } & $13.9 \%$ & $5.1 \%$ & $12.3 \%$ & $10.0 \%$ \\
& 26 & 11 & 19 & 56 \\
\hline Интенсивнее от & $60.4 \%$ & $45.2 \%$ & $20.1 \%$ & $43.4 \%$ \\
1-го лица & 113 & 98 & 31 & 242 \\
\hline Интенсивнее от & $8.0 \%$ & $26.3 \%$ & $48.7 \%$ & $26.3 \%$ \\
3-го лица & 15 & 57 & 75 & 147 \\
\hline \multirow{2}{*}{ Одинакова } & $17.6 \%$ & $23.5 \%$ & $18.8 \%$ & $20.3 \%$ \\
& 33 & 51 & 29 & 113 \\
\hline \multirow{2}{*}{ Итого } & $100 \%$ & $100 \%$ & $100 \%$ & $100 \%$ \\
& 187 & 217 & 154 & 558 \\
\hline
\end{tabular}

Примечание. В верхних строках - процентная доля от общего числа случаев в каждой группе, в нижних - число случаев в абсолютном выражении. Общее число случаев соответствует суммарному количеству заданий (представленных двигательных элементов), выполненных по выборке. 
насыщенных кинестетически при переходе от группы с преобладанием ракурса от 1-го лица к группе с преобладанием ракурса от 3-го лица (от 60.4 до $20.1 \%$ случаев и от 8.0 до $47.8 \%$ случаев, соответственно).

Процентное распределение номинальных вариантов восприятия кинестезии по возрасту (приложение 3) значимо отличается от равномерного $\left(\chi^{2}=1.966 ; p<0.001\right)$ и демонстрирует постепенный рост частоты указания образов с ракурсом от 1-го лица $(r=0.826 ; p=0.000)$ и постепенное снижение частоты указания образов с ракурсом от 3-го лица $(r=-0.719$; $p=0.002)$ как кинестетически более насыщенных по мере увеличения возраста испытуемых, причем данные закономерности достоверно приближаются к линейным ( $\mathrm{F}=24.591$; $p=0.000$; и $\mathrm{F}=10.633 ; p=0.006$ соответственно; см. рисунок 5). При объединении испытуемых в возрастные группы (<14 лет, 14-18 и >18 лет), более равнозначные по количеству субъектов, данная закономерность сохраняется $\left(\chi^{2}=57.030 ; \mathrm{p}<0.001\right)$.

При попарном сравнении с помощью критерия Манна-Уитни групп с преобладанием ракурса от 1-го лица, от 3-го лица или его смены по количественно выраженным значениям кинестезии (см. раздел «Методика») достоверных различий не выявлено. Аналогичным образом не найдено значимых корреляций кинестезии в количественном выражении со средним баллом за ракурс мысленного образа и возрастом.

Корреляционный анализ, выполненный по сумме случаев использования различных видов информации о представленном движении каждым спортсменом, в целом показывает хорошее разделение между заданными конструктами, за исключением оценки движения по ощущению его результата (таблица 3). Учитывая фактический смысл, заложенный в данную переменную, полученные корреляции являются ожидаемыми

PucyHox 5

Процентное распределение вариантов восприятия кинестезии в зависимости от ракурса мысленного образа по возрасту

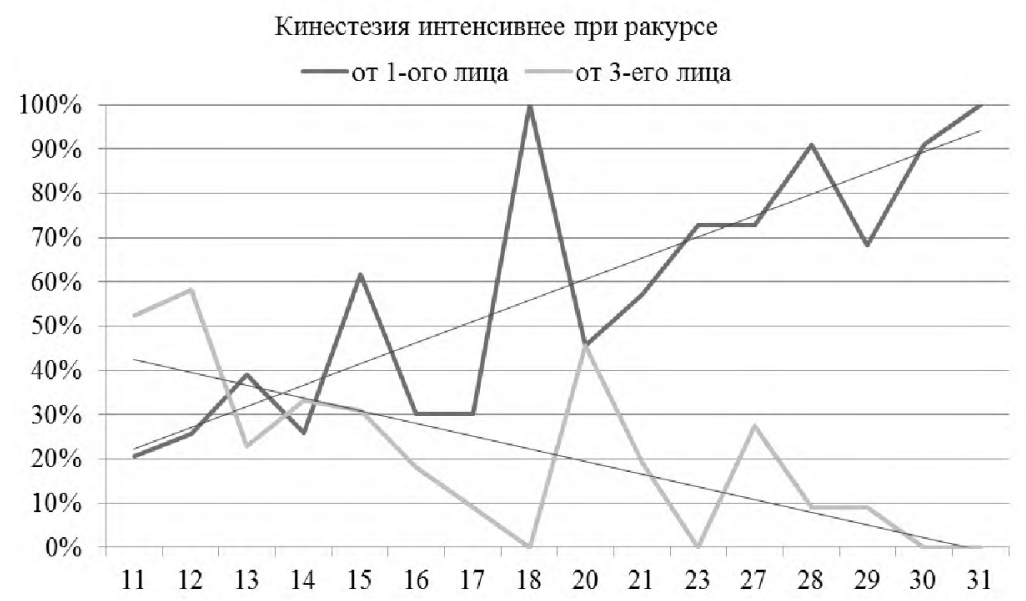


Таблица 3

Корреляционный анализ структуры использования различных видов информации о представленном движении (по Спирмену)

\begin{tabular}{|l|c|c|c|c|}
\hline & $\begin{array}{c}\text { Внешняя } \\
\text { форма }\end{array}$ & Результат & $\begin{array}{c}\text { Мышечная } \\
\text { память» }\end{array}$ & $\begin{array}{c}\text { Ошущение } \\
\text { результата }\end{array}$ \\
\hline Внешняя форма & 1 & $\begin{array}{c}r=0.040 \\
p=0.980\end{array}$ & $\begin{array}{c}r=-0.110 \\
p=0.429\end{array}$ & $\begin{array}{c}r=0.237 \\
p=0.085\end{array}$ \\
\hline Результат & & 1 & $\begin{array}{c}r=-0.140 \\
p=0.312\end{array}$ & $\begin{array}{c}r=0.291 \\
p=0.033\end{array}$ \\
\hline $\begin{array}{l}\text { «ьшшечная } \\
\text { память» }\end{array}$ & & & 1 & $\begin{array}{c}r=0.378 \\
p=0.005\end{array}$ \\
\hline $\begin{array}{l}\text { Ощущение } \\
\text { результата }\end{array}$ & & & & 1 \\
\hline
\end{tabular}

и отражают смещение внимания к результату действия, а также близость мышечно-суставных и вестибулярных рецепций как передающих информацию о движении.

Таблица 4 демонстрирует, что спортсмены, представляющие действия в основном от 3-го лица, значимо чаще других оценивают движения по внешней форме $\left(\chi^{2}=10.826, p=0.004\right)$. В свою очередь, лыжники, преимущественно использующие образы с ракурсом от 1-го лица, значимо чаще остальных полагаются на невизуальные способы оценки движения $\left(\chi^{2}=\right.$ $=22.255, p<0.001)$ и его результата $\left(\chi^{2}=20.598, \mathrm{p}<0.001\right)$. Это подтверждается значимой отрицательной корреляцией $(r=-0.378, p=0.005)$ между оценкой представленных движений по «мышечной памяти», выраженной в виде суммы случаев ее использования каждым спортсменом в отдельности, и средним баллом за ракурс представления двигательных элементов. Визуальную оценку результата движения практически в равной мере предпринимают спортсмены с преобладанием ракурса от 1-го и от 3-го лица, тогда как испытуемые, склонные к смене ракурса в процессе представления, обращаются к ней достоверно реже $\left(\chi^{2}=11.257\right.$, $p=0.004$ ).

Использование оценки представленного движения по «мышечной памяти» и по ощущению его результата в совокупности являет собой «Полезную» кинестезию, задействованную как невизуальный источник информации о движении. Таким образом, чтобы соотнести показатели «полезной» кинестезии и кинестезии, выявленной традиционным опросным методом, мы выполнили распределение случаев использования/неиспользования оценки представленного движения в невизуальной модальности по баллам, отражающим интенсивность кинестезии (таблица 5).

Полученное распределение демонстрирует высокую корреляцию $(r=0.964, p=0.000)$ частоты случаев использования оценки движения в невизуальной модальности с баллом за интенсивность кинестезии. При этом также очевидно, что на фоне 
Таблица 4

Использование различных видов информации о представленных движениях в группах испытуемых, выделенных на основе преобладающего ракурса двигательных образов

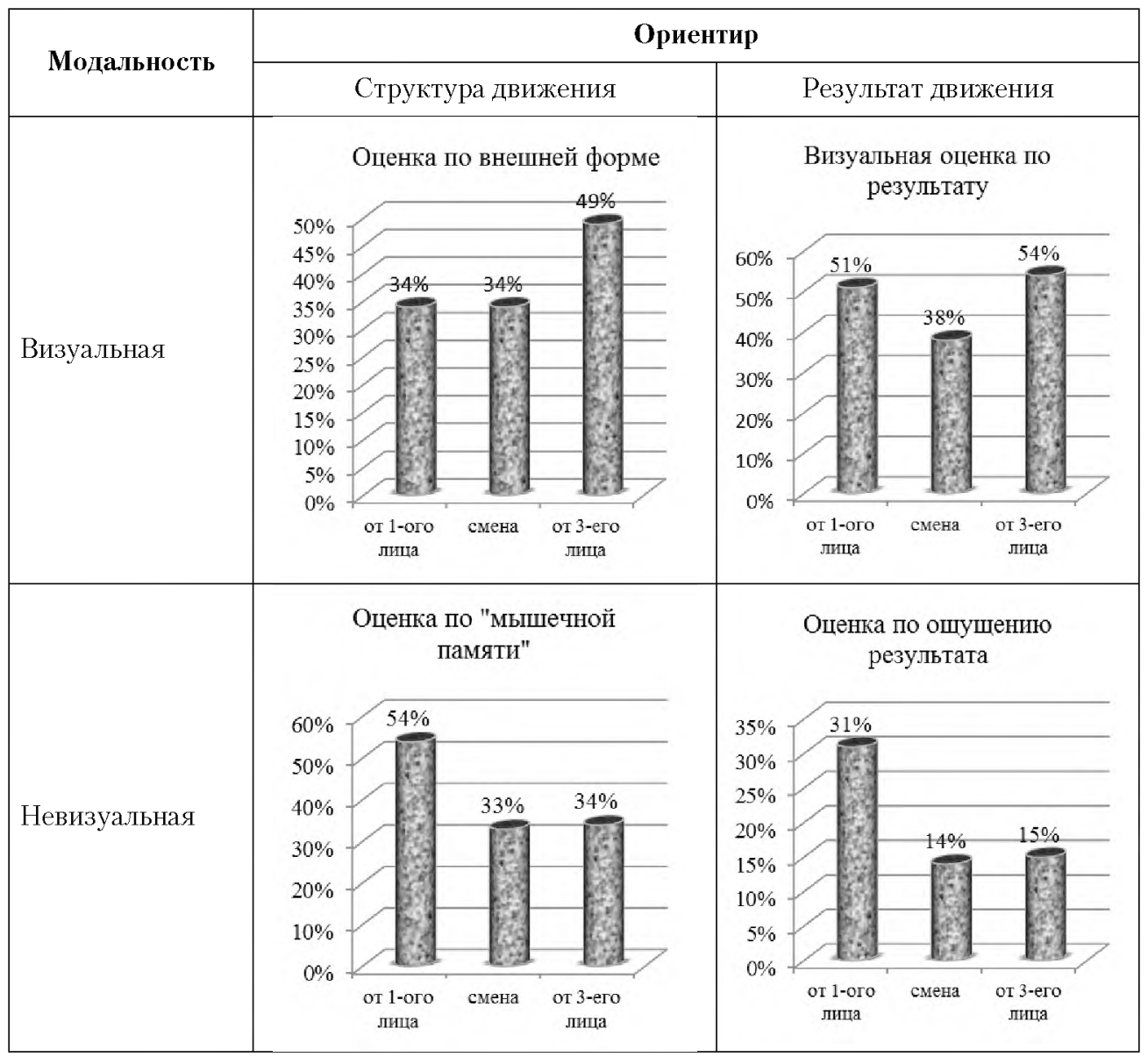

умеренной выраженности кинестезии выявляется существенная доля случаев, в которых оценка движения ни по мышечной памяти, ни по ощущению результата не предпринимается.

Различия по характеру контроля представленных движений между спортсменами разного уровня мастерства отражены на рисунке 6 (распределение достоверно отлича- ется от равномерного: оценки по внешней форме $-\chi^{2}=20.714, p=0.000$; оценки по результату $-\chi^{2}=36.629$, $p=0.000$; оценки по «мышечной памяти» $-\chi^{2}=38.608, p=0.000$; оценки по ощущению результата $\left.\chi^{2}=37.347, p=0.000\right)$.

Данные таблицы 6 демонстрируют, что интенсивность кинестезии по сравнению с другими этапами развития навыка значимо выше на 
Таблица 5

Распределение случаев использования/неиспользования оценки представленного движения в невизуальной модальности по баллам, отражающим интенсивность кинестезии

\begin{tabular}{|c|c|c|c|c|c|c|c|c|c|c|c|}
\hline $\begin{array}{c}\text { Оценка } \\
\text { представленного } \\
\text { движения по } \\
\text { «мьшечной } \\
\begin{array}{c}\text { памяти» и/или } \\
\text { ощущению } \\
\text { результата }\end{array}\end{array}$ & 1 & 2 & 3 & 4 & 5 & 6 & 7 & 8 & 9 & 10 & \\
\hline & & & & & & & & & & & \\
Не используется & 90.9 & 66.7 & 56.8 & 53.7 & 65.0 & 45.0 & 39.6 & 37.7 & 12.5 & 6.4 & 45.0 \\
\hline Используется & 10 & 14 & 21 & 29 & 52 & 27 & 21 & 29 & 3 & 3 & 209 \\
\hline Итого & 9.1 & 33.3 & 43.2 & 46.3 & 35.0 & 55.0 & 60.4 & 62.3 & 87.5 & 93.6 & 55.0 \\
& 100.0 & 7 & 16 & 25 & 28 & 33 & 32 & 48 & 21 & 44 & 255 \\
\hline
\end{tabular}

Примечание. В верхних строках - процентная доля от общего числа случаев для каждого значения интенсивности кинестезии, в нижних - число случаев в абсолютном выражении. Случаи полного отсутствия кинестезии не учитываются.

Рисунок 6

Использование выделенных способов контроля представленных движений на различных уровнях мастерства

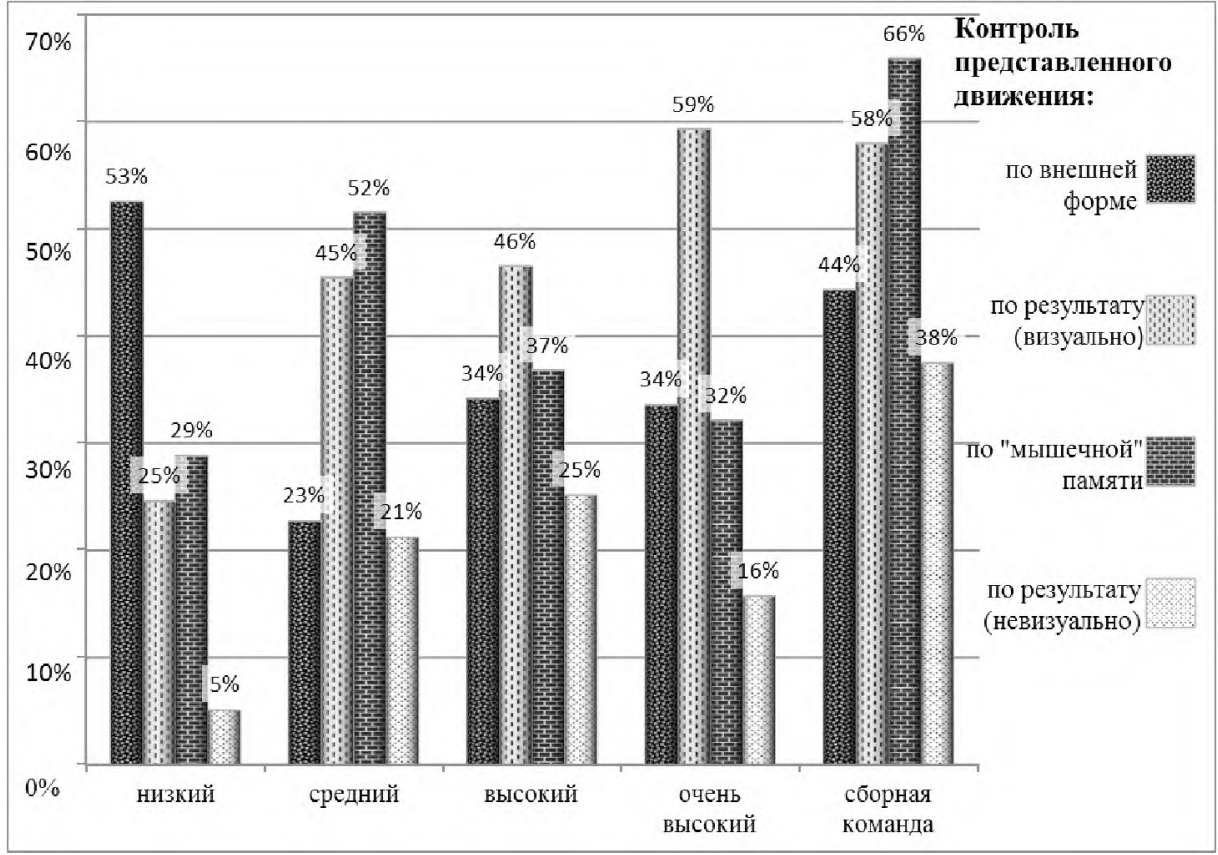


среднем уровне мастерства и на уровне сборной команды, где наиболее часто используется оценка движения по «мышечной памяти».

Возрастные различия по частоте использования разных источников информации о представленном движении (таблица 7) выявляются только в отношении оценки по «мышечной памяти» с группой респондентов старше 18 лет. Учитывая, что в данную группу вошли в основном члены сборной команды, мы приходим к выводу о том, что реальных возрастных различий по использованию разных способов оценки представленного движения в выборке нет, а полученные результаты отражают специфичность сборной команды как обособленного контингента испытуемых. Значимых корреляций между возрастом и характеризующей каждого спортсмена суммой случаев использования отдельно взятых способов оценки

Таблица 6

Попарное сравнение уровней мастерства по интенсивности кинестезии (в количественном выражении)

\begin{tabular}{|c|c|c|c|c|c|c|c|c|c|}
\hline \multicolumn{10}{|c|}{ Уровень мастерства } \\
\hline $\mathrm{H} / \mathrm{C}$ & $\mathrm{H} / \mathrm{B}$ & $\mathrm{H} / \mathrm{OB}$ & $\mathrm{H} / \mathrm{CK}$ & $\mathrm{C} / \mathrm{B}$ & $\mathrm{C} / \mathrm{OB}$ & $\mathrm{C} / \mathrm{CK}$ & $\mathrm{B} / \mathrm{OB}$ & $\mathrm{B} / \mathrm{CK}$ & $\mathrm{OB} / \mathrm{CK}$ \\
\hline$<$ & & & $<$ & $>$ & $>$ & & & $<$ & $<$ \\
2531.5 & & & 3654.5 & 3486.0 & 3096.0 & & & 5100.5 & 4710.0 \\
0.001 & & & 0.004 & 0.001 & 0.004 & & & 0.004 & 0.049 \\
\hline
\end{tabular}

Примечание. Обозначение уровней мастерства: $\mathrm{H}$ - низкий, $\mathrm{C}-$ средний, В - высокий, ОВ - очень высокий, СК - сборная команда.

Для всех значимых различий и тенденций к ним указаны: в верхних строках - знак, характеризующий сравнение указанных групп по заданной переменной, в средних - значение критерия U Манна-Уитни, в нижних - p-значение.

Таблица 7

Различия по частоте использования способов контроля представленного движения между возрастными группами

\begin{tabular}{|c|c|c|c|c|}
\hline \multirow{2}{*}{$\begin{array}{c}\text { Возрастные } \\
\text { групшы }\end{array}$} & \multicolumn{4}{|c|}{ Способ контроля представленного движения } \\
\cline { 2 - 5 } & $\begin{array}{c}\text { По внешней } \\
\text { форме }\end{array}$ & $\begin{array}{c}\text { По результату } \\
\text { (визуально) }\end{array}$ & $\begin{array}{c}\text { По «мышечной } \\
\text { памяти» }\end{array}$ & $\begin{array}{c}\text { По оцущению } \\
\text { результата }\end{array}$ \\
\hline$<14 / 14-18$ & & & 60.5 & \\
\hline$<14 />18$ & & & 0.058 & \\
\hline $14-18 />18$ & & & 70.5 & \\
\hline
\end{tabular}

Примечание. Для всех достоверных различий и тенденщий к ним приведены: в верхних строках - значение критерия U Манна-Уитни, в нижних $-p$-значение. 
представленных движений не обнаружено.

\section{Обсуждение результатов}

В целом результаты нашего эксперимента подтверждают мнение М. Спиттла (Spittle, 2001), Н. Каллоу и Л. Харди (Callow, Hardy, 2004) и других авторов о том, что квазиперцепции кинестетической модальности могут возникать в составе образов с ракурсом как от 1-го, так и от 3-го лица. Так, участники настоящего исследования испытывали «чувство движения», представляя от 1-го лица в $76.1 \%$ случаев, и от 3-го лица в $70.8 \%$ случаев (см. рисунок 4), что, на наш взгляд, убедительно демонстрирует сопоставимость ракурсов по признаку наличия кинестетических ощущений. Более того, так же, как и Н. Каллоу и Л. Харди (Ibid.), мы столкнулись со значительным числом случаев, когда при представлении от 3-го лица кинестезия была даже более интенсивной, чем при представлении от 1-го. Но в целом мы могли бы отметить по выборке умеренную склонность воспринимать кинестетические ощущения с большей интенсивностью при представлении от 1-го лица. Мы предполагаем, что причиной этого является сопряженность ракурса от 1-го лица с узким фокусом внимания (Каминский, Веракса, 2016), способствующим высокой концентрации на деталях представленного движения, в том числе на кинестетических ощушениях.

По мнению М. Грегг с соавт. (Gregg et al., 2010), отчетливость кинестезии является важным показателем индивидуальной способности к полноценному и реалистичному представлению движений. По данным Дж. Камминг и Д. Стэ-Мэри (Cumming, Ste-Marie, 2001), такая способность развивается по мере того, как спортсмены используют воображение для проработки необходимых двигательных навыков. Если учитывать, что чаще всего у спортсменов отмечается выраженная предрасположенность к представлению с какого-либо одного ракурса (Spittle, 2001), то и способность создавать яркие реалистичные образы этого ракурса должна быть выше. В результате преобладающий ракурс отчетливее передает представляемое движение и все ощушения, сопряженные с ним. По всей видимости, это и имело место при восприятии кинестезии в исследованной выборке, ведь в $78.1 \%$ случаев респонденты указывали, что представить движение с непривычного ракурса для них сложнее.

Промежуточное положение смены ракурса по отношению к представлениям стабильно от 1-го или от 3-го лица при определении интенсивности кинестезии (таблица 2) характеризует ее как переходное состояние, в определенной мере уравнивающее субъективную значимость представлений с одного и другого ракурса и вероятность их вклада в свойства образа с меняющимся ракурсом.

Необходимо отметить, что частота использования кинестезии для оценки представленного движения («полезная» кинестезия), по данным таблицы 5, составляет 55\% случаев, тогда как частота ее восприятия в образе как таковой - 90\% случаев (таблица 2), что, на наш взгляд, является весьма существенным расхождением. Это может свидетельствовать о том, что сам вопрос о 
наличии в образе квазиперцепций кинестетической модальности создает установку на их целенаправленный поиск, выражающуюся в сознательных попытках прочувствовать представленное движение, что может быть не характерно для привычного представления двигательной активности, а значит, может искажать его. Следовательно, данные по кинестетической модальности образа, полученные опросным методом, не стоит приравнивать к данным по ее действительному использованию субъектами в качестве источника информации о движении. В таком случае кинестезия, скорее, является критерием реалистичности созданного образа (в частности, способности прочувствовать представленное движение), которая так или иначе способствует эффективной мысленной проработке двигательного навыка (Robin et al., 2007).

Различия в результатах, полученных при изучении кинестезии в номинальном и количественном выражении, не являются противоречием и объясняются разным содержанием этих переменных. Так, в случае c номинальным выражением интенсивность кинестезии в образе доминирующего ракурса определяется относительно внутреннего референта (интенсивности кинестезии в образе противоположного ракурса у того же субъекта), который может иметь как большую интенсивность, так и меньшую. В случае с количественным выражением интенсивность кинестезии в образе доминирующего ракурса определяется относительно внешнего референта формулировки, ограничивающей интенсивность кинестезии минимально возможным (принимаемым за 0 баллов полное отсутствием кинестезии) и максимально возможным (принимаемую за 10 баллов интенсивность кинестезии реально выполняемого движения) значением, при этом интенсивность кинестезии в образе недоминирующего ракурса не учитывается.

Выявленные возрастные различия в соотношении кинестезии и ракурса могут быть прокомментированы с позиции данных, полученных в одном из последних зарубежных исследований (Yu et al., 2016). Согласно описанной указанными авторами закономерности, способность представлять движения от 1-го лица с опытом растет у всех спортсменов, тогда как способность к представлению от 3-го лица характерно возрастает только в тех видах спорта, где необходимо принимать решения, исходя из действий соперника. Учитывая, что лыжные гонки не подразумевают прямого взаимодействия между спортсменами, в соответствии с указанной закономерностью можно ожидать, что если исходно у юных лыжников может быть более выражена способность к представлению от 3-го лица (в том числе в кинестетической модальности), то в дальнейшем под влиянием специфичных виду спорта факторов будет развиваться только способность к представлению от 1-го лица.

Полученные нами данные о способах оценки представленного движения свидетельствуют о том, что использование каждого из них возможно при любом преобладающем ракурсе образов и уровне спортивного мастерства, однако существуют значимые закономерности, связанные 
как с первым, так и со вторым параметром.

Так, ракурс от 1-го лица все же в большей мере предрасполагает к использованию невизуальной оценки движения, чем представления со сменой ракурса или от 3-го лица, что ранее предполагалось многими авторами (Jowdy et al., 1989; Hale, 1998), однако оставалось спорным ввиду двояких результатов исследования кинестетической модальности обра3а. Ракурс от 3-го лица позволяет более активно предпринимать оценку движения по его внешней форме, что хорошо согласуется с данными Л. Харди и Н. Каллоу (Hardy, Callow, 1999), подтвердившими более высокую эффективность представлений от 3-го лица при проработке движений со строго определенной пространственной конфигурацией. Таким образом, мы можем констатировать адаптивность психики спортсменов, которая стремится реализовать решение поставленной задачи самым эффективным способом. Относительно редкое использование всех способов контроля в случае смены ракурса можно объяснить тем, что его переключение, вероятно, само по себе требует больше когнитивных ресурсов, которые в случае представления стабильно от 1-го или от 3-го лица могут быть задействованы в оценке представленного движения.

Различия в структуре используемых источников информации о представленном движении на разных уровнях мастерства (рисунок 6) во многом иллюстрируют описанные Н.А. Бернштейном (1990) перестройки управления реальным движением, происходящие по мере совершенствования двигательного навыка. Так, на низком уровне мастерства доминирующим способом контроля является оценка соответствия внешней формы представленного движения ее субъективному эталону. Это можно связать с характерным для данного этапа дефицитом двигательного опыта, который обусловливает возможность использования только визуальных рецепций в качестве эталонных. С ростом мастерства оценку внешней формы на доминирующей позиции замещает «мышечная память», что свидетельствует об активно идущем процессе выявления сенсорных коррекций соответствующей модальности, ведь субъект, заинтересованный в освоении навыка, начиная упражняться, уже склонен анализировать поступающие от мышц ощущения, тем самым подменяя визуальный двигательный эталон кинестетическим. Дальнейшим этапом является автоматизация навыка, когда, согласно Н.А. Бернштейну (1990), возникает конфликт между сознательным вниканием в структуру движения и его плавным автоматическим выполнением. Одним из условий последнего является переключение внимания с собственно движения на двигательную задачу. Как следствие, на ведущее место в управлении автоматизированными движениями должны выходить эталоны, отражающие намеченный результат двигательного действия. На связь оценки по результату с автоматизацией движения, помимо ее доминирования на высоком и очень высоком уровнях мастерства, указывают отрицательные корреляции с показателем деавтоматизации движения $(r=-0.340$, $p=0.021, n=46)$ и разностью между 
числом циклов во втором и в первом забегах $(r=-0.423, p=0.003, n=46)$. Наиболее равномерное использование различных способов контроля наблюдается в сборной команде, где, однако, основная роль среди них вновь отводится оценке представленного движения с опорой на «мышечную память». Причиной этого могут быть повышенные требования, предъявляемые к технической подготовке спортсменов такого класса, с чем хорошо согласуется доминирование образов с ракурсом от 1-го лица на данном уровне мастерства (Каминский и др., 2017; Каминский, Веракса, 2016).

\section{Заключение}

Результаты настоящей статьи позволяют сделать предварительный вывод о неравнозначности данных о кинестезии, полученных с помощью традиционных опросных методов, и фактического использования кинестетической модальности в качестве источника информации о представленном движении. Так, при изучении контроля представленного движения была выявлена достоверная склонность спортсменов к использованию кинестезии при оценке правильности образов с ракурсом от 1-го лица, тогда как при исследовании кинестетической модальности данная закономерность просматривалась менее отчетливо ввиду того, что более яркие кинестетические квазиперцепции воспринимались спортсменами также и на фоне образов преобладающего ракурса. В связи с этим мы склонны считать, что большинство имеющихся на сегодняшний день данных о кинестетической модальности двигательного образа необходимо расценивать как данные о способности к созданию полимодального образа, являющейся критерием яркости и реалистичности представлений.

На основе признаков модальности и характера содержания мысленного образа в настоящей статье выделено четыре типа источников информации о представленном движении: его внешняя форма, визуальный результат, мышечное чувство и ошущение результата.

Учитывая, что полученные нами данные по использованию внешней формы в качестве способа контроля представленного движения хорошо согласуются с результатами известных формирующих экспериментов (Hardy, Callow, 1999), можно с уверенностью рекомендовать проработку движения с помощью образов с ракурсом от 3-го лица в случае, если необходимо освоить двигательный навык, опираясь на его строго определенную пространственную конфигурацию. С другой стороны, если основным источником информации о движении для спортсмена служит кинестезия, то наиболее эффективным в проработке двигательных навыков должен быть преобладающий ракурс (хотя с большей вероятностью это все же будет ракурс от 1-го лица). По результатам анализа используемых на различных уровнях мастерства источников информации о представленном движении подтверждено, что наибольшая потребность в кинестетической модальности образа существует на этапе выявления сенсорных коррекций до автоматизации навыка.

Поскольку структура источников информации о представленных движениях на различных уровнях 
мастерства аналогична той, что уже описана для фактически выполняемых движений (Бернштейн, 1990), можно предполагать, что на всем протяжении совершенствования дви- гательного навыка сохраняется эквивалентность между контролем (и, следовательно, обеспечивающей его мозговой активностью) реально и мысленно исполненного движения.

\section{Литература}

Барабанщикова, В. В. (2005). Модальность образной сферы как фактор оптимизации фуикционального состояния профессионалов в процессе психологической саморегулящии (Кандидатская диссертация). МГУ имени М.В. Ломоносова, Москва.

Бернштейн, Н. А. (1990). Физиология движений и активность. М.: Изд-во «Наука».

Веракса, А. Н., Горовая, А. Е. (2011). Модели использования образов в спортивной психологии. Психологическая наука и образование, 1. Режим доступа: http://psyedu.ru/journal/2011/1/2069.phtml

Веракса, А. Н., Леонов, С. В., Горовая, А. Е. (2011) Психологические особенности художественньг гимнасток. Вестник Московского университета, Серия 14. Психология, 4, 134-147.

Дубровский, Д.И. (2007). Сознание, мозг, искусственный интеллект: сборник статей. М.: ИД «Стратегия-центр».

Елшанский, С. П. (2014). Проприоцептивная память позы руки. Психология, социология и педаzогика, 3. Режим доступа: http://psychology.snauka.ru/2014/03/2905

Каминский, И. В., Алмазова, О. В., Веракса, А. Н. (2017) Взаимосвязь ракурса образов с освоенностью и спецификой представляемых движений. Психологиеский журнал, 38(4), 76-92.

Каминский, И. В., Веракса, А. Н. (2016). Ракурс психического образа и его роль в мысленной проработке двигательных навыков. Вестник Санкт-Петербургского университета. Серия 16. Психология и педагогика, 2, 27-37.

Каминский, И. В. (2015). Контроль ракурса образов как средство повышения эффективности мысленной проработки двигательных навыков. Вестник Московского университета, 14. Психология, 4, 83-97.

Новикова, Н. Б. (2014). Применение видеоанализа в процессе научно-методического обеспечения сборной команды России по лыжным гонкам. В кн. Нтоговый сборник Всероссийской наудиопрактииеской конферении с международным уиастием «Итоги выступления спортивных сборных команд Российской Федерапии на ХХІІ Олимпийских зимних играх в г. Соии» (с. 130-134).

Раменская, Т. И. (1999). Техпиеская подготовка лыжиика: учебио-практииеское пособие. М.: Физкультура и спорт.

Ссылки на зарубежсые источники см. в разделе References после англоязыиного блока.

Каминский Игорь Владиславович - соискатель, кафедра психологии образования и педагогики, факультет психологии, МГУ имени М.В. Ломоносова.

Сфера научных интересов: психология спорта; педагогическая психология; психофизиология; механизмы построения двигательной активности; механизмы и корреляты формирования моторных навыков; применение методик на основе мысленного образа в различных сферах деятельности; взаимосвязь действия и его мысленного образа; роль внимания и сенсорной модальности в репрезентационных процессах.

Контакты: min5drav@mail.ru 
Алмазова Ольга Викторовна - доцент, кафедра возрастной психологии, факультет психологии, МГУ имени М.В. Ломоносова, кандидат психологических наук.

Сфера научных интересов: возрастная психология; психология развития; акмеология; роль привязанности к матери в развитии личности на разных этапах онтогенеза; взаимоотношения взрослых сиблингов; личностное и профессиональное становление; решение задач развития подросткового и юношеского возраста.

Контакты: almaz.arg@gmail.com

Веракса Александр Николаевич - и.о. заведующего, кафедра психологии образования и педагогики, факультет психологии, МГУ имени М.В. Јомоносова, член-корреспондент PAO, доктор психологических наук, доцент.

Сфера научных интересов: психология спорта, педагогическая психология, когнитивное развитие, когнитивные средства, развитие регуляции.

Контакты: veraksa@yandex.ru

Приложение 1

Образец задания с опросным блоком, использованным для выявления особенностей мысленных образов

\section{1. Вынос палок не ниже уровня макушки}

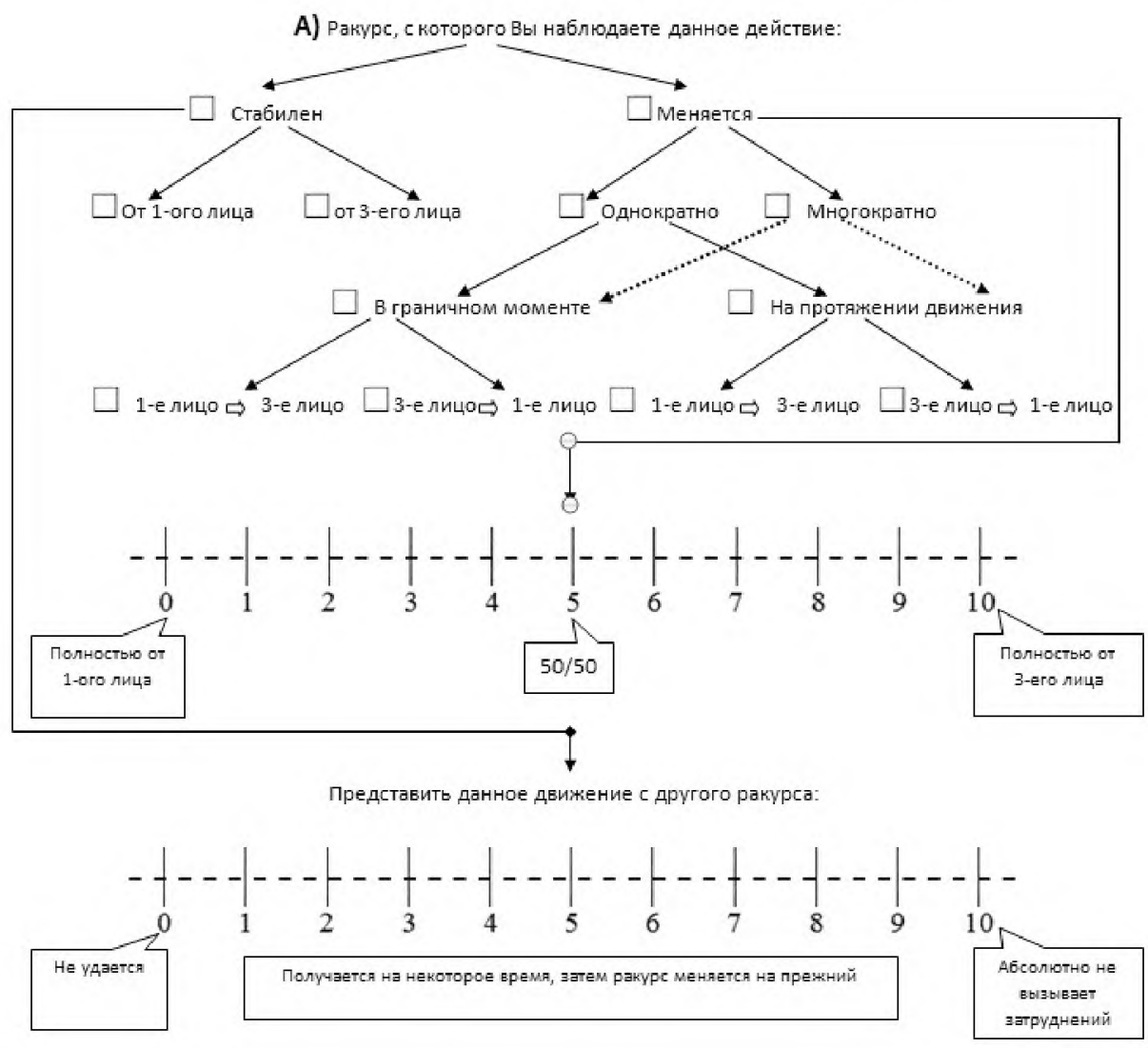




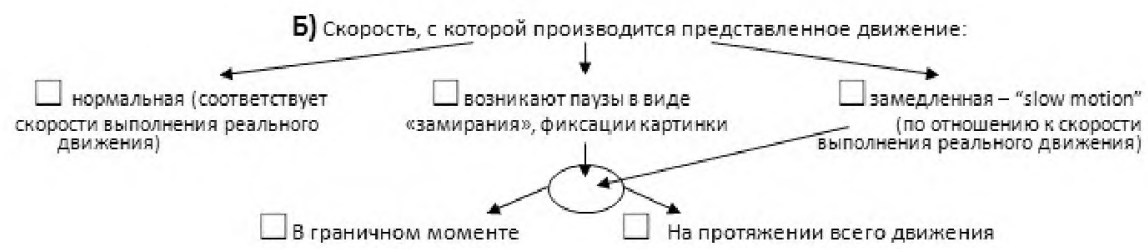

В) Когда я представляю данный элемент:

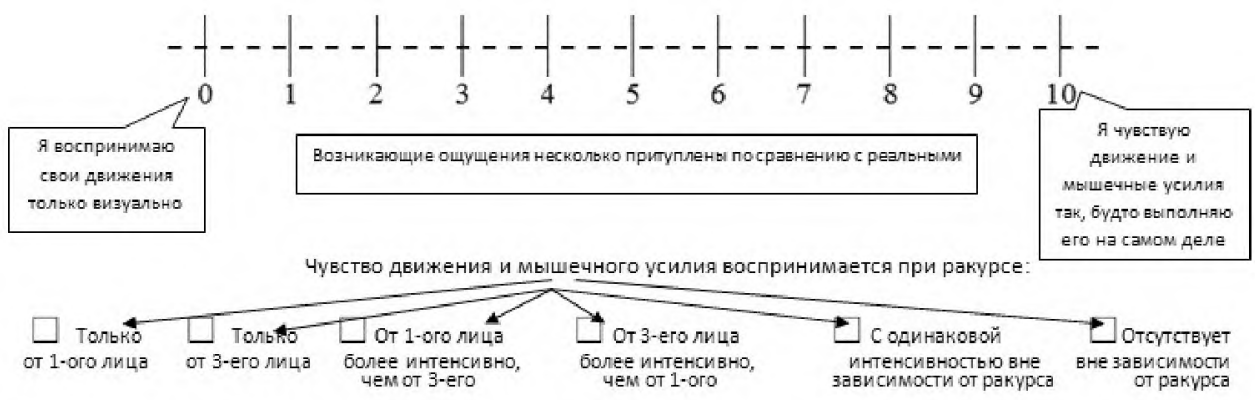

Г) Оценивая, насколько совершенно данное движение выполнено мысленно, Вы опираетесь на:

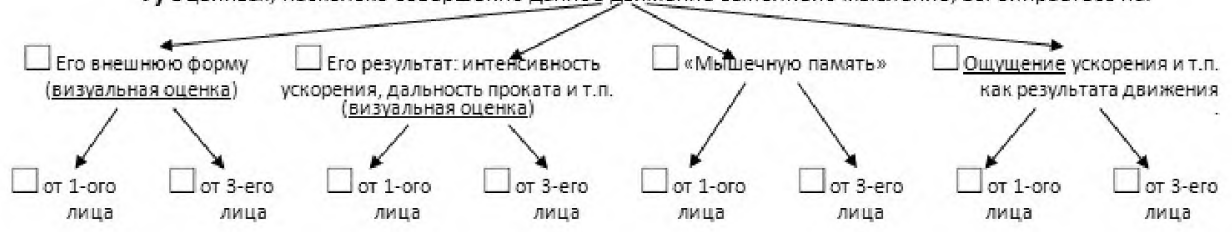

Приложение 2

Пример варианта дополнительного задания с соответствующим ему ключом в уменьшенном масштабе

1.

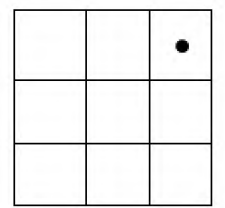

4.

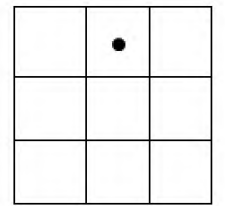

2.

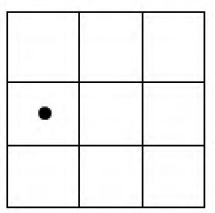

5.

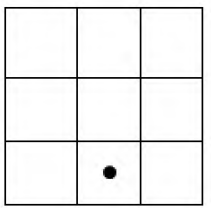

3.

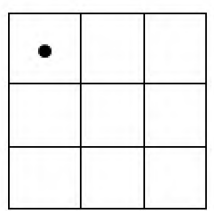

Ключ.

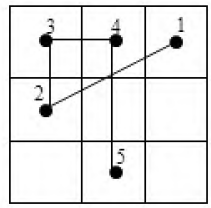


Распределение выраженности кинестезии в зависимости от ракурса мысленного образа по возрасту

\begin{tabular}{|c|c|c|c|c|c|c|c|c|c|c|c|c|c|c|c|c|c|}
\hline \multirow[b]{2}{*}{ Кинестезия } & \multicolumn{16}{|c|}{ Возраст (лет) } & \multirow[t]{2}{*}{ Итого } \\
\hline & $\begin{array}{l}11 \\
(4)\end{array}$ & $\begin{array}{c}12 \\
(4)\end{array}$ & $\begin{array}{c}13 \\
(12)\end{array}$ & $\begin{array}{c}14 \\
(6)\end{array}$ & $\begin{array}{c}15 \\
(5)\end{array}$ & $\begin{array}{c}16 \\
(6)\end{array}$ & $\begin{array}{c}17 \\
(3)\end{array}$ & $\begin{array}{c}18 \\
(1)\end{array}$ & $\begin{array}{l}20 \\
(1)\end{array}$ & $\begin{array}{l}21 \\
(2)\end{array}$ & $\begin{array}{l}23 \\
(1)\end{array}$ & $\begin{array}{l}27 \\
\text { (1) }\end{array}$ & $\begin{array}{l}28 \\
(1)\end{array}$ & $\begin{array}{c}29 \\
(2)\end{array}$ & $\begin{array}{l}30 \\
(1)\end{array}$ & $\begin{array}{l}31 \\
(1)\end{array}$ & \\
\hline Отсутствует & $\begin{array}{c}15.9 \\
7\end{array}$ & $\begin{array}{l}0 \\
0\end{array}$ & $\begin{array}{c}14.5 \\
19\end{array}$ & $\begin{array}{c}13.6 \\
9\end{array}$ & $\begin{array}{c}3.6 \\
2\end{array}$ & $\begin{array}{c}21.2 \\
14\end{array}$ & $\begin{array}{c}0.0 \\
0\end{array}$ & $\begin{array}{c}0.0 \\
0\end{array}$ & $\begin{array}{c}9.1 \\
1\end{array}$ & $\begin{array}{c}14.3 \\
3\end{array}$ & $\begin{array}{c}0.0 \\
0\end{array}$ & $\begin{array}{c}0.0 \\
0\end{array}$ & $\begin{array}{c}0.0 \\
0\end{array}$ & $\begin{array}{c}4.5 \\
1\end{array}$ & $\begin{array}{c}0.0 \\
0\end{array}$ & $\begin{array}{c}0.0 \\
0\end{array}$ & $\begin{array}{c}10.0 \\
56\end{array}$ \\
\hline $\begin{array}{l}\text { Интенсивнее } \\
\text { при ракурсе от } \\
\text { 1-го лица }\end{array}$ & $\begin{array}{c}20.5 \\
9\end{array}$ & $\begin{array}{c}25.6 \\
11\end{array}$ & $\begin{array}{c}38.9 \\
51\end{array}$ & $\begin{array}{c}25.8 \\
17\end{array}$ & $\begin{array}{c}61.8 \\
34\end{array}$ & $\begin{array}{c}30.3 \\
20\end{array}$ & $\begin{array}{c}30.3 \\
10\end{array}$ & $\begin{array}{c}100.0 \\
11\end{array}$ & $\begin{array}{c}45.5 \\
5\end{array}$ & $\begin{array}{c}57.1 \\
12\end{array}$ & $\begin{array}{c}72.7 \\
8\end{array}$ & $\begin{array}{c}72.7 \\
8\end{array}$ & $\begin{array}{c}90.9 \\
10\end{array}$ & $\begin{array}{c}68.2 \\
15\end{array}$ & $\begin{array}{c}90.9 \\
10\end{array}$ & $\begin{array}{c}100.0 \\
11\end{array}$ & $\begin{array}{l}43.4 \\
242\end{array}$ \\
\hline $\begin{array}{l}\text { Интенсивнее } \\
\text { при ракурсе от } \\
\text { 3-го лица }\end{array}$ & $\begin{array}{c}52.3 \\
23\end{array}$ & $\begin{array}{c}58.1 \\
25\end{array}$ & $\begin{array}{c}22.9 \\
30\end{array}$ & $\begin{array}{c}33.3 \\
22\end{array}$ & $\begin{array}{c}30.9 \\
17\end{array}$ & $\begin{array}{c}18.2 \\
12\end{array}$ & $\begin{array}{c}9.1 \\
3\end{array}$ & $\begin{array}{c}0.0 \\
0\end{array}$ & $\begin{array}{c}45.5 \\
5\end{array}$ & $\begin{array}{c}19.0 \\
4\end{array}$ & $\begin{array}{c}0.0 \\
0\end{array}$ & $\begin{array}{c}27.3 \\
3\end{array}$ & $\begin{array}{c}9.1 \\
1\end{array}$ & $\begin{array}{c}9.1 \\
2\end{array}$ & $\begin{array}{c}0.0 \\
0\end{array}$ & $\begin{array}{c}0.0 \\
0\end{array}$ & $\begin{array}{l}26.3 \\
147\end{array}$ \\
\hline Одинакова & $\begin{array}{c}11.4 \\
5\end{array}$ & $\begin{array}{c}16.3 \\
7\end{array}$ & $\begin{array}{c}23.7 \\
31\end{array}$ & $\begin{array}{c}27.3 \\
18\end{array}$ & $\begin{array}{c}3.6 \\
2\end{array}$ & $\begin{array}{c}30.3 \\
20\end{array}$ & $\begin{array}{c}60.6 \\
20\end{array}$ & $\begin{array}{c}0.0 \\
0\end{array}$ & $\begin{array}{c}0.0 \\
0\end{array}$ & $\begin{array}{c}9.5 \\
2\end{array}$ & $\begin{array}{c}27.3 \\
3\end{array}$ & $\begin{array}{c}0.0 \\
0\end{array}$ & $\begin{array}{c}0.0 \\
0\end{array}$ & $\begin{array}{c}18.2 \\
4\end{array}$ & $\begin{array}{c}9.1 \\
1\end{array}$ & $\begin{array}{c}0.0 \\
0\end{array}$ & $\begin{array}{c}20.3 \\
113\end{array}$ \\
\hline Итого & $\begin{array}{c}100 \\
44\end{array}$ & $\begin{array}{c}100 \\
43\end{array}$ & $\begin{array}{l}100 \\
131\end{array}$ & $\begin{array}{c}100 \\
66\end{array}$ & $\begin{array}{c}100 \\
55\end{array}$ & $\begin{array}{c}100 \\
66\end{array}$ & $\begin{array}{c}100 \\
33\end{array}$ & $\begin{array}{c}100 \\
11\end{array}$ & $\begin{array}{c}100 \\
11\end{array}$ & $\begin{array}{c}100 \\
21\end{array}$ & $\begin{array}{c}100 \\
11\end{array}$ & $\begin{array}{c}100 \\
11\end{array}$ & $\begin{array}{c}100 \\
11\end{array}$ & $\begin{array}{c}100 \\
22\end{array}$ & $\begin{array}{c}100 \\
11\end{array}$ & $\begin{array}{c}100 \\
11\end{array}$ & $\begin{array}{l}100 \\
558\end{array}$ \\
\hline
\end{tabular}

Примечание. В верхних строках - процентная доля от общего числа случаев для каждого возраста, в нижних - число случаев в абсолютном выражении. Общее число случаев соответствует суммарному количеству заданий (представленных двигательньх элементов), выполненных по выборке. 


\title{
Kinaesthesia and Sources of Information on Movements Imagined from 1-st or 3-d Person Perspective in Cross-Country Skiers with Various Level of Expertise
}

\author{
I.V. Kaminskiy ${ }^{\mathrm{a}}$, O.V. Almazova ${ }^{\mathrm{a}}$, A.N. Veraksa ${ }^{\mathrm{a}}$ \\ ${ }^{a}$ Lomonosov Moscow State University, GSP-1, Leninskie Gony, Moscow, 119991, Russian Federation
}

\begin{abstract}
The present article is dedicated to the study of an imagery perspective as a form of mental image with a set of distinct properties in terms of its use in sports. In addition to kinesthetic modality, which is traditionally viewed by sports psychologists as such a property, we have studied the use of different modes of imagined movement appraisal at various levels of sports expertise. The sample consisted of 54 ski racers in maximum possible range of ranking. The subjects imagined their own performance of V1 skating technique successively concentrating on 8 elements, which had been taken as a basis for 11 imagination task items. Each imagination task was accompanied by filling in the specially constructed report form, which collected data on imagery perspective and kinesthetic modality as well as on modes of imagined movements control, differentiated by modality (visual/ non-visual) and appraisal criterion (movement structure/ result). Sport expertise was determined based on expert assessment of technical merit of $7 \mathrm{~V} 1$ skating elements used as a part of the imagination task and number of cycles in two 100 -meter roller-ski skating trials, one of which had been conducted in the dual-task settings. Groups of the subjects were formed according to their prepotent imagery perspective, as well as to their level of expertise, by means of cluster analysis. Corresponding distributions within the groups formed on the basis of the prepotent perspective showed that intensity of kinesthesia is higher in cases of the prepotent perspective, whereas increased frequency of use of visual and non-visual control modes is associated with third- and first-person imagery perspective, respectively. Distribution of modes of control on expertise is consistent with already known laws for real movements confirming equivalence of underlying processes in action and mental image.
\end{abstract}

Keywords: sport psychology, mental imagery, motor imagery, mental training, mental practice, imagery perspective, imagery modality, kinesthetic imagery, kinesthesia, control of imagined movement, motor skills, cross country skiing.

\section{References}

Abernethy, B., Summers, J. J., Ford, S. (1998). Issues in the measurement of attention. In J. L. Duda (Ed.), Advances in sport and exercise psychology measurement (pp. 173-194). Morgantown, WV: Fitness Information Technology.

Barabanshikova, V.V. (2005). Modal'nost' obraznoj sfery kak faktor optimizatsii funktsional'nogo sostoyaniya professionalov v processe psikhologicheskoj samoreguljatsii. [Modality of the sphere of imagery as a factor of optimization of the functional state of professionals in the process of psychological self-regulation] (Ph.D. dissertation). Lomonosov Moscow State University, Moscow, Russian Federation. 
Bernstein, N. A. (1990). Physiology of movements and activity. Moscow: Nauka.

Callow, N., \& Hardy, L. (2004). The relationship between the use of kinaesthetic imagery and different visual imagery perspectives. Joumal of Sports Sciences, 22, 167-177.

Cumming, J. L., \& Ste-Marie, D. M. (2001). The cognitive and motivational effects of imagery training: A matter of perspective. The Sport Psychologist, 15, 276-288.

Dubrovskii, D. I. (2007). Soznanie, mozg, iskusstvennyi intellekt [Cognition, brain, artificial intelligence]. Moscow: Strategiia-Tsentr.

Gregg, M., Hall, C., \& Butler, A. (2010). The MIQ-RS: A suitable option for examining movement imagery ability. Evidence Based Complementary and Alternative Medicine, 2(2), 249-257.

Guillot, A., Desliens, S., Rouyer, Ch., \& Rogovski, I. (2013). Motor imagery and tennis serve performance: the external focus efficacy. Joumal of Sports Science and Medicine, 12(2), 332-338.

Hale, B. D. (1998). Imagery training: A guide for sports people. Leeds: National Coaching Foundation.

Hardy, L., \& Callow, N. (1999). Efficacy of external and internal visual imagery perspectives for the enhancement of performance on tasks in which form is important. Joumal of Sport and Exercise Psychology, 21, 95-112.

Ives, J. C. (2013). Motor behavior: Connecting mind and body for optimal performance. Philadelfia, PA: Lippincott Williams \& Wilkins.

Jeannerod, M. (1994).The representing brain: neural correlates of motor intention and imagery. Brain Behav. Sci., 17, 187-245.

Jowdy, D. P., Murphy, S. \& Durtschi, S. K. (1989). An assessment of the use of imagery by elite athletes: Athlete, coach and psychologist perspective. United States Olympic Committee Report. Colorado Springs, CO: US Olympic Committee.

Kaminskiy, I. V. (2015). Kontrol' rakursa obrazov kak sredstvo povyshenija jeffektivnosti myslennoj prorabotki dvigatel'nyh navykov [Control of the perspective of the images as a way to increase effectiveness of the mental elaboration of the motor skills]. Vestnik Moskovskogo Universiteta. Seria 14. Psikhologiya, 4, 83-97.

Kaminskiy, I. V., \& Veraksa, A. N. (2016). Rakurs psihicheskogo obraza i ego rol' v myslennoj prorabotke dvigatel'nyh navykov [The perspective of the psychic image and its role in the mental elaboration of the motor skills]. Vestnik Sankt-Peterburgskogo universiteta. Seria 16. Psikhologiya $i$ Pedagogika, 2, 27-37.

Kaminskiy, I. V., Almazova, O. V., \& Veraksa, A. N. (2017). Vzaimosvjaz' rakursa obrazov s osvoennost'ju i specifikoj predstavljaemyh dvizhenij [Interrelation of imagery perspective and imagined movement specifics and expertise]. Psikhologicheskii Zhurnal, 38(4), 76-92.

Novikova, N. B. (2014). Primenenie videoanaliza v processe nauchno-metodicheskogo obespechenija sbornoj komandy Rossii po lyzhnym gonkam [Application of the videoanalysis in the process of methodological support of the representative Russian team in cross-country skiing]. In Itogoryj sbornik Vserossijskoj nauchno-prakticheskoj konferencii s mezhdunarodnym uchastiem "Itogi vystuplenija sportivmyh sbormyh komand Rossijskoj Federacii na XXII Olimpijskih zimnih igrah v g. Sochi" [The resulting proceedings of the All-Russian applied conference with international participation "Results of display of the representative sports teams of the Russian Federation at the $22^{\text {nd }}$ Winter Olympic games in Sochi”] (pp. 130-134).

Ramenskaja, T. I. (1999). Tehnicheskaja podgotovka lyzhnika. [Technical training of a skier]. Moscow: Fizkultura i Sport. 
Robin, N., Dominique, L., Toussaint, L., Blandin, Y., Guillot, A., \& Le Her, M. (2007). Effect of motor imagery training on service return accuracy in tennis: The role of imagery ability. International Journal of Sport and Exercise Psychology, 2, 175-186.

Spittle, M. (2001). Preference for imagery perspective, imagery perspective training and task performance (Doctoral dissertation). Melbourne, Australia.

Veraksa, A. N., \& Gorovaya, A. E. (2011). Modeli ispol'zovanija obrazov v sportivnoj psihologii. [Models of usage of imagery in sports psychology]. Psihologicheskaja Nauka i Obrazovanie psyedu.ru, 1. Retrieved from http://psyedu.ru/journal/2011/1/2069.phtml

Veraksa, A. N., Leonov, S. V., \& Gorovaya, A. E. (2011). Psihologicheskie osobennosti hudozhestvennyh gimnastok. [Psychological qualities of rhythmic gymnasts]. Vestnik Moskovskogo Universiteta. Seria 14. Psikhologiya, 4, 134-147.

Yelshansky, S. P. (2014). Proprioceptivnaja pamjat' pozy ruki [Proprioceptive memory of a posture of a hand]. Psikhologiya, Sociologija i Pedagogika, 3. Retrieved from http://psychology.snauka.ru/ 2014/03/2905

Yu, Q. H., Fu, A. S., Kho, A., Li, J., Sun, X. H., Chan, C. C. (2016). Imagery perspective among young athletes: Differentiation between external and internal visual imagery. Joumal of Sport and Health Science, 5(2), 211-218.

Igor V. Kaminskiy - Ph.D. student, Department of Educational Psychology and Pedagogics, Faculty of Psychology, Lomonosov Moscow State University.

Research area: sport psychology, educational psychology, psychophysiology, mechanisms of movement construction, mechanisms and correlates of motor skills acquisition, application of mental imagery-based methods in various activities, interrelation of action and its mental image, role of attention and sensory modality in representational processes.

E-mail: min5drav@mail.ru

Olga V. Almazova - associate professor, Department of Developmental Psychology, Faculty of Psychology, Lomonosov Moscow State University, Ph.D.

Research area: developmental psychology, acmeology, role of attachment to mother in personality development at various ontogenetical stages, adult siblings interrelations, personal and professional formation, solutions for developmental enhancement in adolescence.

E-mail: almaz.arg@gmail.com

Alexander N. Veraksa - head, Department of Psychology of Education and Pedagogy, Lomonosov Moscow State University, D.Sc.

Research area: sport psychology, educational psychology, cognitive development, cognitive tools, regulation development.

E-mail: veraksa@yandex.ru 